Document downloaded from:

http://hdl.handle.net/10251/63923

This paper must be cited as:

Glanc, M.; Sophocleous, M.; Atkinson, J.; García-Breijo, E. (2013). The effect on performance of fabrication parameter variations of thick-film screen printed silver/silver chloride potentiometric reference electrodes. Sensors and Actuators A: Physical. 197:1-8. doi:10.1016/j.sna.2013.03.036

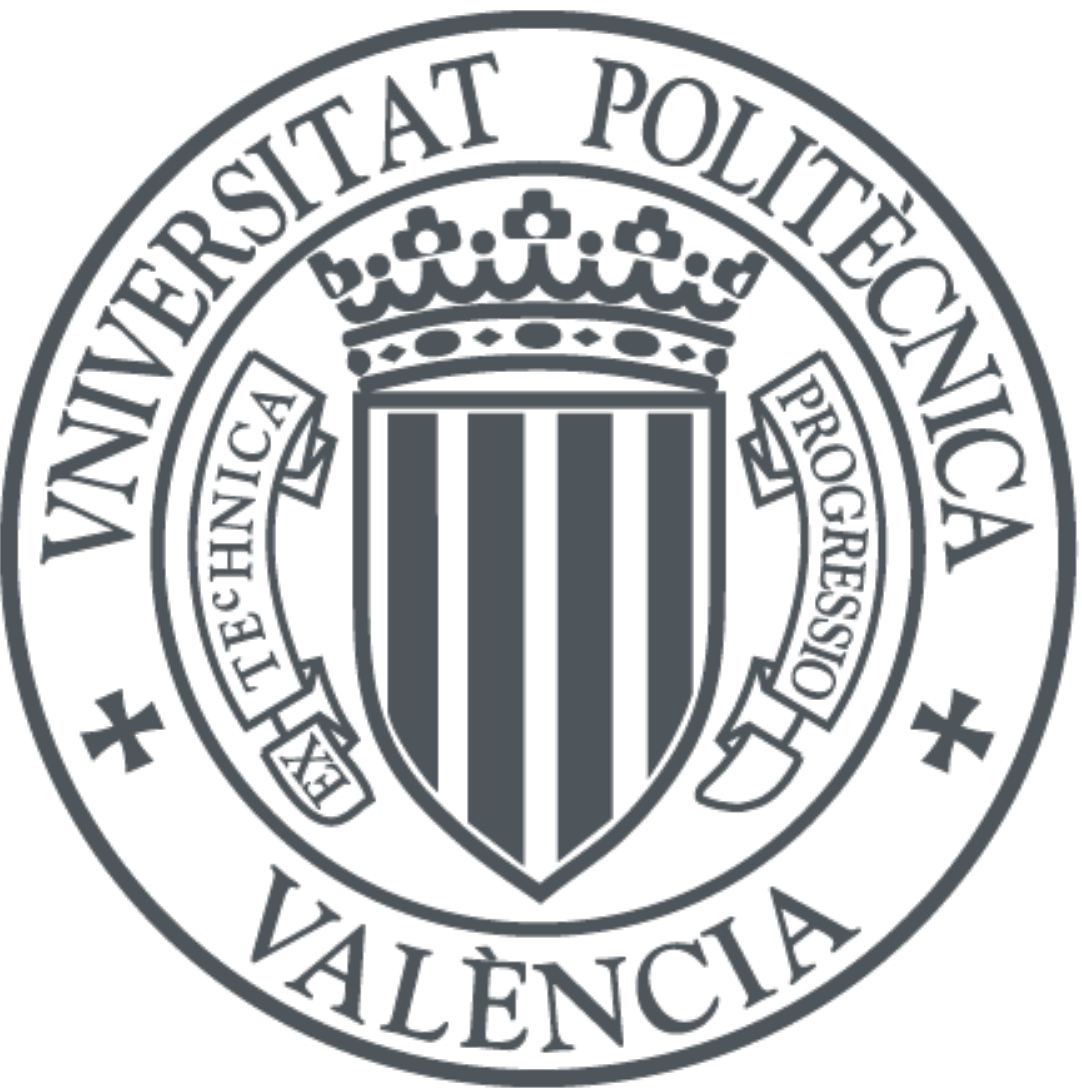

The final publication is available at

http://dx.doi.org/10.1016/j.sna.2013.03.036

Copyright Elsevier

Additional Information 


\title{
The Effect on Performance of Fabrication Parameter Variations of Thick-Film Screen Printed Silver/Silver Chloride Potentiometric Reference Electrodes
}

\author{
M. Glanc ${ }^{1 *}$, M. Sophocleous ${ }^{1 *}$, J. K. Atkinson ${ }^{1}$, E. Garcia-Breijo ${ }^{2}$ \\ ${ }^{1}$ Faculty of Engineering and the Environment, University of Southampton, United Kingdom \\ ${ }^{2}$ Instituto de Reconocimiento Molecular y Desarrollo Tecnológico, \\ Universidad Politécnica de Valencia, Spain
}

\begin{abstract}
Thick-film screen printed silver-silver chloride $(\mathrm{Ag} / \mathrm{AgCl})$ reference electrodes have been fabricated and investigated as an alternative to liquid electrolyte $\mathrm{Ag} / \mathrm{AgCl}$ reference electrodes. The performance of the electrodes was examined with variations of the potassium chloride $(\mathrm{KCl})$ concentration in the final (top) layer of the electrode. Also, different types of binder (glass and polymer) were tested for the underlying $\mathrm{Ag} / \mathrm{AgCl}$ layer. The addition of another layer on top of the $\mathrm{KCl}$ containing salt matrix layer has been found to provide a better stability in varying concentrations of $\mathrm{KCl}$ test solutions. The electrodes were found to give a satisfactory performance when tested for stability in different $\mathrm{pH}$ solutions.
\end{abstract}

\section{Introduction}

There has been a growing interest in the development of new, miniaturised and low cost electrochemical sensors suitable for industrial, biomedical and environmental applications [1]. Thick film technologies together with electrochemical methods embrace the requirements for these devices by giving cost competitive solutions for the fabrication of compact, rugged and robust systems [1]. Thick film chemical sensors offer alternative solutions and allow flexible design with a wide range of materials, low cost infrastructure and mass production capability [2-4].

The silver/silver chloride $(\mathrm{Ag} / \mathrm{AgCl})$ reference electrode is a reference electrode of the 'second kind' [5] and is the simplest and most practical type of reference electrode used in industry and research. The response of any electrochemical potentiometric electrode is meaningless without a reference electrode against which comparisons can be made [6]. Most commercially available $\mathrm{Ag} / \mathrm{AgCl}$ reference electrodes are of the fragile and expensive conventional type of electrolyte-filled devices. The thick-film devices reported here are implemented on the same principle as the conventional electrolyte-filled $\mathrm{Ag} / \mathrm{AgCl}$ reference electrode in that they attempt to mimic its operation through the immobilizing of salt reservoirs in the form of salt matrix layers fabricated as upper layers of a planar design that are in contact with the analyte [7]. The conventional commercial silver/silver chloride reference electrode has a relatively simple construction. It consists of a silver metal electrode coated with silver chloride which is immersed in a saturated filling solution and enclosed in a glass or plastic tube separated from the test solution via a porous plug [8]. The typical planar structure of the thick film equivalent consists of a silver back contact, a waterproofing layer, a silver/silver chloride interfacial layer and one or more overlapping salt matrix layers containing typically potassium chloride $(\mathrm{KCl})$ powder in a lower layer and potassium nitrate $\left(\mathrm{KNO}_{3}\right)$ powder in an upper layer. This double layer approach mimics the double junction type of liquid electrolyte reference electrode that typically contains two liquid electrolytes separated by a porous plug. The research reported here investigates variation of the fabrication parameters of screen-printed thick-film $\mathrm{Ag} / \mathrm{AgCl}$ reference electrodes, such as salt concentration, layer thickness and interfacial layer material types, and their effect on sensor characteristics. The monitoring of electrode potentials in different test solutions over time has been used as a method to determine hydration times, drift rates, stability and useful lifetime of the devices. A major aspect of the investigation has been the focus on the electrode stability and response time across different ionic concentration solutions arising from the addition of different types of salt containing outer layers. The results contribute towards optimisation of the fabrication parameters of low cost miniaturised screen-printed $\mathrm{Ag} / \mathrm{AgCl}$ reference electrodes and demonstrate the feasibility of the development of a miniaturised alternative to the commercially available liquid electrolyte filled $\mathrm{Ag} / \mathrm{AgCl}$ reference electrode through the use of thick-film technology. 
The classic commercially available silver/silver chloride reference electrode typically consists of a silver wire coated with silver chloride and surrounded by a saturated solution of $\mathrm{KCl}$ (approximately 3.5M) [5]. The silver/silver chloride layer forms the interaction between the ion movement in the $\mathrm{KCl}$ solution and the electron movement in the silver wire. In the idealised system the internal element is at equilibrium:

$$
\operatorname{AgCl}_{(s)}+e^{-} \leftrightarrow A g_{(s)}+C l_{(a q)}^{-}
$$

The equilibrium potential $(\mathrm{E})$ of the electrode is defined by the Nernst equation:

$$
E=E^{\theta}+\left(\frac{R T}{n F}\right) \ln \frac{\left(a_{\text {oxi }}\right)}{\left(a_{\text {Red }}\right)}
$$

Where $E^{\theta}$ is the standard potential $(\mathrm{V}) ; R$ is the universal gas constant $\left(8.314 \mathrm{JK}^{-1} \mathrm{~mol}^{-1}\right) ; T$ is the absolute temperature $(\mathrm{K}) ; n$ is the number of moles of electrons transferred in the reaction; $F$ is the Faraday constant (96485 $\mathrm{C} \mathrm{mol}^{-1}$ ); $a$ is the activity; Oxi is the oxidant and Red is the reductant. In the case of the $\mathrm{Ag} / \mathrm{AgCl}$ electrode (2) can be re-written as:

$$
E=E^{\theta}+\left(\frac{R T}{n F}\right) \ln \frac{\left(a_{A g C l}\right)}{\left(a_{A g}\right)\left(a_{C l^{-}}\right)}
$$

The activity of a species $a$, is defined as the product of the activity coefficient of the specific substance and its concentration. When the species is at its standard state the activity coefficient can be approximated to 1 . In the case of $\mathrm{AgCl}$ and $\mathrm{Ag}$, since they are in the solid state, their activity can be equated to their concentrations therefore Eqn. (3) can be expressed as:

$$
E=E^{\theta}-\left(\frac{R T}{n F}\right) \ln \left[a_{C l^{-}}\right]+\left(\frac{R T}{n F}\right) \ln \frac{[A g C l]}{[A g]}
$$

The Nernst equation for a cell at a nominal room temperature of $25^{\circ} \mathrm{C}$ is frequently expressed in terms of base 10 logarithms, with numerical values replacing the constant coefficients and hence re-writing Eqn. (4) gives:

$$
E=E^{\theta}-0.0592 \log \left(a_{C l^{-}}\right)+0.0592(k)
$$

Where $k$ is the concentration ratio of $\mathrm{Ag}$ to $\mathrm{AgCl}$. The measured electrode is said to display Nernstian behaviour when its potential $(E)$ decreases by approximately $59 \mathrm{mV}$ for every decade change in chloride ion concentration at $25^{\circ} \mathrm{C}$ and provided that the activity coefficient of chloride ion in the solution is approximately equal to unity. $\mathrm{AgCl}$ is a sparingly soluble salt therefore the solution will become saturated very quickly, which will keep the activity of $\mathrm{AgCl}$ constant regardless of the immersed solution. The activity of $\mathrm{Ag}$ is controlled by the activity solubility product which is invariant at a certain temperature whilst the activity solubility product is the product of the silver ion activity and the chloride ion activity and hence the potential of the electrode depends on the chloride ion activity of the solution surrounding the electrode.

\section{Fabrication process}

The electrodes were screen printed onto $50 \mathrm{~mm}$ x $50 \mathrm{~mm}, 0.625 \mathrm{~mm}$ thick, $96 \%$ alumina substrates (Coorstech). Each substrate was divided into six equal sized electrodes and prescribed with laser lines so that individual electrodes could be easily snapped off along those lines. Therefore, a simultaneous six electrode fabrication was possible as shown in Figure 1.

The electrodes were constructed by successive screen printing of each individual layer. The screen designs for each layer were produced using AUTOCAD to give precise dimensions of the mesh openings and each screen was designed to print a single layer of the electrode. The first layer was the silver conductor so the screen mesh opening was a rectangle with dimensions of $4.61 \mathrm{~mm}$ x $44.56 \mathrm{~mm}$. On top of that, a waterproofing layer with a rectangular shape of $6.5 \mathrm{~mm} \times 43.8 \mathrm{~mm}$ was deposited, leaving a small window exposing the underlying silver. The window size was a square of $3.4 \mathrm{~mm} \times 3.4 \mathrm{~mm}$ while a part of the silver, approximately $4.17 \mathrm{~mm} \times 4.61$ $\mathrm{mm}$, was also left exposed at one end for soldering connecting wires, as can be seen in Figure 1. The screen for the $\mathrm{Ag} / \mathrm{AgCl}$ layer was a square window of $4 \mathrm{~mm} \times 4 \mathrm{~mm}$, slightly bigger than the exposed silver to ensure all the silver was covered. The last two screens (for $\mathrm{KCl}$ and for $\mathrm{KNO}_{3}$ ) had simple square mesh openings, like the $\mathrm{Ag} / \mathrm{AgCl}$ window, but with increasing dimensions of $4.5 \mathrm{~mm} \times 4.5 \mathrm{~mm}$ and $5 \mathrm{~mm} \times 5 \mathrm{~mm}$ respectively, to ensure complete coverage of the previous layer. 


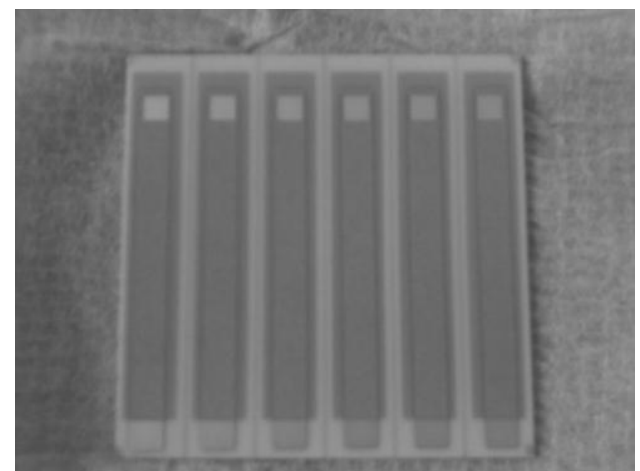

Figure 1: Six simultaneously fabricated reference electrode test strips on a $50 \mathrm{~mm}$ x $50 \mathrm{~mm}$ alumina substrate, only the first two layers are present in this case

The screens for first three layers were made from stainless steel with 250 lines per inch, 15 micron emulsion and $45^{\circ}$ mesh while the last two were polymer $70 \mathrm{~W}$ PW $123-70 \mathrm{~W}: 133 \mu \mathrm{m}$ with photopolymer emulsion POLYCOL UNO: $113 \mu \mathrm{m}$ thickness. All the screens were manufactured for the Aurel C880 Printer by MCI Cambridge. The silver conductor layer was printed using ESL-9912 ink, on top of which a glass dielectric insulator (ESL 4905-C) was deposited to isolate the conductor from the electrolyte. Different types of $\mathrm{Ag} / \mathrm{AgCl}$ inks were tested, both polymer and glass based binders, as well as different weight ratios of polymer to $\mathrm{KCl}$ as the top layer. The polymer $\mathrm{KCl}$ layer was printed using a silicone based ink (ESL 242-SB). The reason different screen types were used was for ease of printing the polymer ESL 242-SB with added $\mathrm{KCl}$, and in order to ensure that the $\mathrm{KCl}$ grains would pass through the mesh opening. $\mathrm{KCl}$ (Analytical Reagent, Fisher Scientific UK Ltd) was milled into powder of grains smaller than $100 \mu \mathrm{m}$ and was directly added to the ESL 242-SB paste, adding ESL 402 solvent when required to keep the paste in printable condition.

The construction procedure described above is designed to mimic the construction of a single junction gel-filled commercial reference electrode. Double junction gel-filled reference electrodes are generally found to be more stable and more reliable in time, so in an attempt to improve the stability of the thick-film electrodes, some double junction thick-film reference electrodes were fabricated. The only difference of these electrodes to those described previously is that another layer of ESL 242-SB containing $\mathrm{KNO}_{3}$ with 1:4 weight ratio was printed on top of the polymer/ $\mathrm{KCl}$ layer.

Three different types of $\mathrm{Ag} / \mathrm{AgCl}$ layer were used. One was a polymer based paste provided by Gwent Electronic Materials (GEM C61003P7), the other two types where glass based inks provided by Universidad de Politécnica de Valencia, Spain. The glass bound $\mathrm{Ag} / \mathrm{AgCl}$ layers were fabricated from two screen printable pastes that were prepared as follows. Type 1 (Valencia PPCFC3): AgCl (Aldrich 227927) milled to 400 $\mathrm{rpm} / 30 \mathrm{~min}$ with ethanol (Pulverisette Fritsch), sieve/100 $\mu \mathrm{m}, \mathrm{Ag}$ (Aldrich 32708-5) sieve/100 $\mu \mathrm{m}$, powder frit (Ferro CF7567FC) sieve/100 $\mu \mathrm{m}$, vehicle (Heraeus V-006), mixed in the ratios $3 \mathrm{gr} \mathrm{Ag}+3 \mathrm{gr} \mathrm{AgCl}+2 \mathrm{gr}$ frit + $3.84 \mathrm{gr}$ vehicle and triple roll milled for 5 minutes. Type 2 (Valencia PPCFB2) is exactly the same as Type 1 with the exception of a different powder frit (Ferro EG2020VEG).
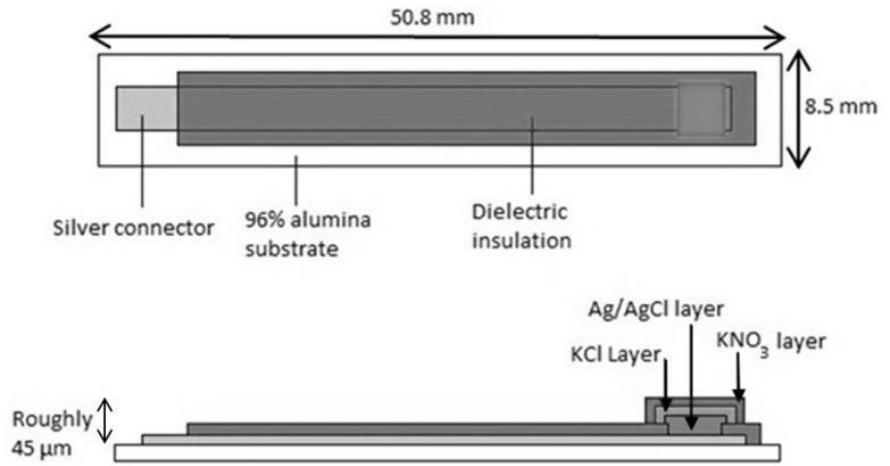

Figure 2: The construction of a Screen-Printed $\mathrm{Ag} / \mathrm{AgCl}$ reference electrode 
The first two layers were held at room temperature for 10 minutes after printing to allow relaxation of surface stresses and then dried in a DEK 1209 infrared mini dryer at $125^{\circ} \mathrm{C}$ for 15 minutes. They were then cured in a 6 zone belt furnace (BTU VQ41) at a peak temperature of $850^{\circ} \mathrm{C}$ with an ascent and descent of $50^{\circ} \mathrm{C} / \mathrm{min}$ and held at peak temperature for 10 minutes. Drying and curing temperatures for each of the pastes comprising the subsequent layers are as detailed in Table 1 below.

Table 1: Curing temperatures and times for each layer

\begin{tabular}{cccccc}
\hline Layer & Paste & $\begin{array}{c}\text { Drying } \\
\text { temperature } \\
\left({ }^{\circ} \mathrm{C}\right)\end{array}$ & $\begin{array}{c}\text { Drying } \\
\text { time }(\mathrm{min})\end{array}$ & $\begin{array}{c}\text { Curing } \\
\text { temperature } \\
\left({ }^{\circ} \mathrm{C}\right)\end{array}$ & $\begin{array}{c}\text { Curing } \\
\text { time (min) }\end{array}$ \\
\hline $\begin{array}{c}\text { Silver } \\
\text { conductor }\end{array}$ & ESL-9912-A & 125 & $10-15$ & 850 & $\sim 45$ \\
$\begin{array}{c}\text { Dielectric } \\
\text { insulator }\end{array}$ & ESL-4905-C & 125 & $10-15$ & 850 & $\sim 45$ \\
$\begin{array}{c}\text { Glass } \\
\text { Ag/AgCl }\end{array}$ & PPCFB2 & 150 & 10 & 420 & $\sim 30$ \\
$\begin{array}{c}\text { Glass } \\
\text { Ag/AgCl }\end{array}$ & PPCFC3 & 150 & 10 & 390 & $\sim 30$ \\
$\begin{array}{c}\text { Polymer } \\
\text { Ag/AgCl }\end{array}$ & C61003P7 & 60 & 30 & & - \\
Polymer & & & & & \\
KCl \& & ESL-242-SB & 125 & 10 & 150 & 30 \\
KNO3 & & & & & \\
\hline
\end{tabular}

\section{Experimental Setup}

The performance and stability of the electrodes was tested by measuring their electro potential difference with respect to a commercial gel-filled single junction reference electrode (Beckman Coulter A57193). Three electrodes of each type were tested by soldering wires onto their exposed silver conductor layers and connecting them to the voltmeter. Measurements were carried out using an own design portable data logger. The output signals of the multi-electrodes were acquired using a 36:1 multiplexer architecture, which was formed by two 18:1 channel MOS analogue multiplexers (MAX306, MAXIM) and one 2:1 channel analogue multiplexer (MAX308, MAXIM) thus up to 36 channels could be measured simultaneously. The selection of each channel in the multiplexer was controlled by the microcontroller (PIC18F4550). The sampling rate for the 36 channels was one electrode every $100 \mathrm{~ms}$ in periods of 10s. A precision CMOS quad micro power operational amplifier (LMC646, NATIONAL SMC), was connected to the output multiplexer. This operational amplifier has very high input impedance and an ultra-low input bias current of less than 16fA and hence is suited to the signal impedance generated by the potentiometric multi-electrodes. An analogue to digital converter (ADC) (MAX128, MAXIM) with a resolution of 12-bits that can work with either unipolar or bipolar input signals was used. It uses an external or internal reference voltage in order to obtain different full scale ranges. In this case a $2.5 \mathrm{~V}$ external reference and a bipolar input signal were used. With this configuration the resolution (equivalent to 1 Least Significant Bit) was $1.22 \mathrm{mV}$. The PIC18F4550 microcontroller gathered the data from the ADC using the $\mathrm{I}^{2} \mathrm{C}$ bus. The PIC18F4550 was selected for its low power consumption (sleep mode currents down to $0.1 \mu \mathrm{A}$ typical), $32 \mathrm{~K}$ of memory program and $2 \mathrm{~K}$ of RAM and USB port. The software for the PIC18F4550 microcontroller has been designed to scan the voltage for each channel. In the process of measurement, the data were sent to the PC via an RS232 serial communications. The acquisition software was developed using Visual Basic ${ }^{\circledR} 6.0$ and Microsoft Excel® 2003 software.

A block diagram of the measurement system is shown in Figure 3 together with photographs in Figures 4 and 5. 


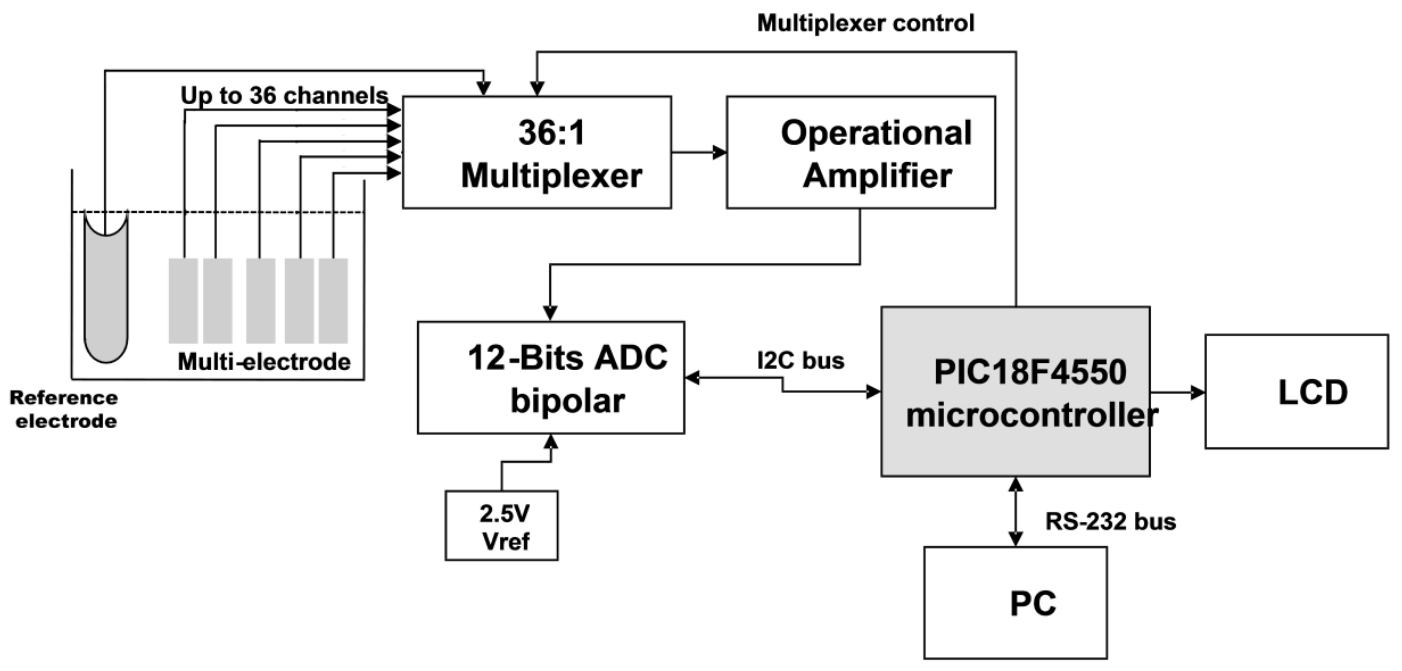

Figure 3: Block diagram of the measurement system
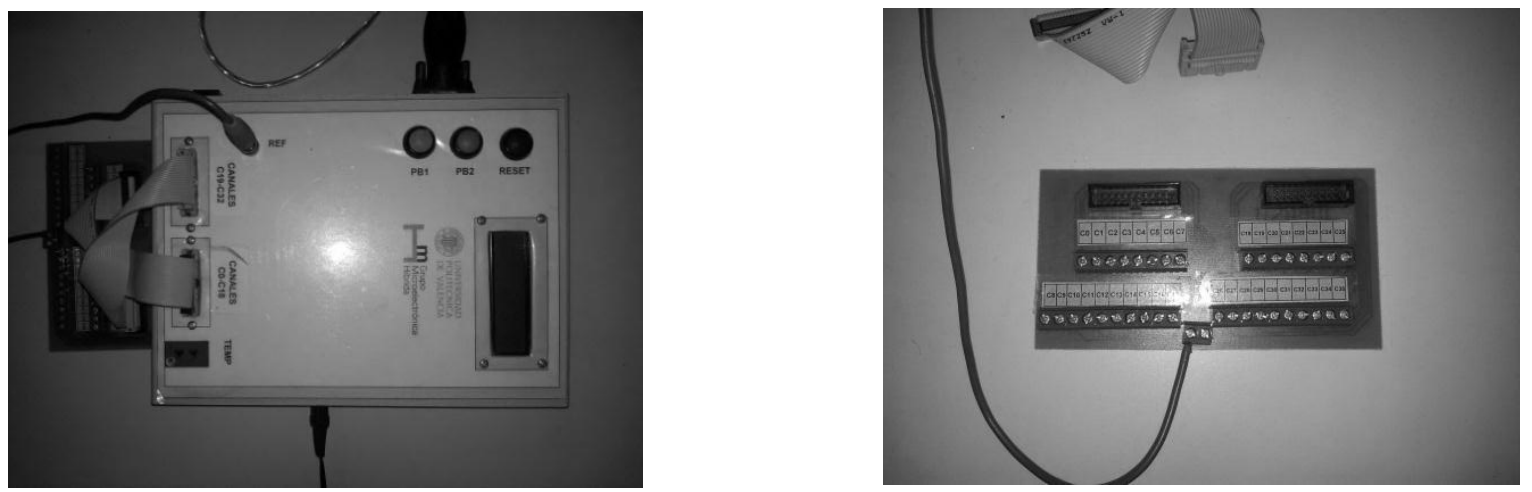

Figure 4: Data Logger on the left and the connection card on the right

The electrodes were attached to a transparent plastic mounting plate that was designed to support the electrodes and immerse only their working part in a test solution, this configuration is shown in Figure 5.

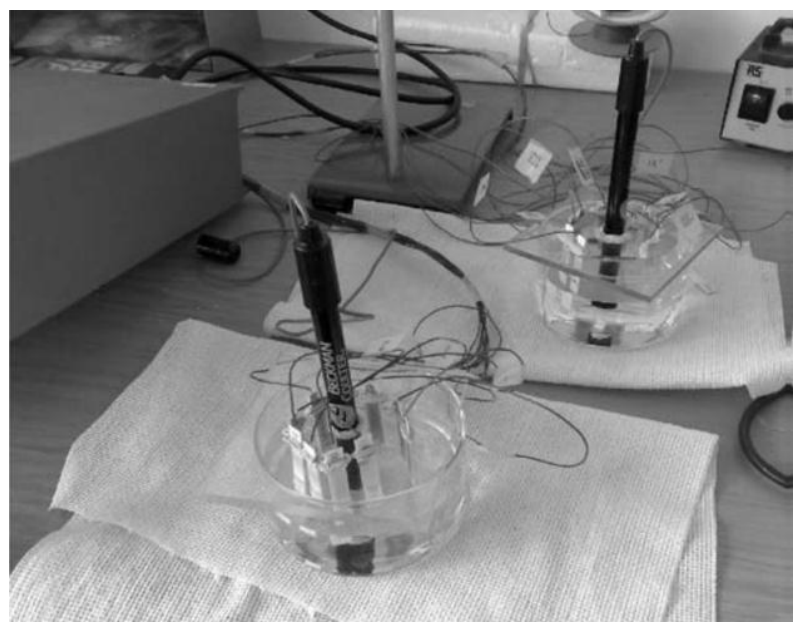

Figure 5: Experimental Setup 
The solutions were stirred constantly during testing by a magnetic stirrer to minimise the effect of mass transport from the solution to the electrodes, which is more important at lower concentrations. The experiments were all performed at room temperature of $20 \pm 3^{\circ} \mathrm{C}$ and it is believed that these small variations in temperature can be considered insignificant since the electrode potential sensitivity to temperature is known to be very low. The electrodes were tested in different $\mathrm{KCl}$ solutions made by dissolving $\mathrm{KCl}$ salt (Analytical Reagent, Fisher Scientific UK Ltd) in de-ionised water. Each set of electrodes was firstly hydrated into a $0.134 \mathrm{M}(\mathrm{mol} / \mathrm{L}) \mathrm{KCl}$ solution overnight and the time sampling interval used for the hydration period was 300 seconds. The hydration period is always required to establish equilibrium of the reversible reaction occurring at the electrode, as shown in Figure 6. After hydration, the electrodes were successively immersed in different concentrations of $\mathrm{KCl}$ solutions that were prepared by adding a weighed amount of $\mathrm{KCl}$ into $0.4 \mathrm{~L}$ of distilled water. For every amount of $\mathrm{KCl}$ dissolved the concentration was calculated in terms of molarity based on (6)

$$
\text { Molarity }=\frac{\text { actual mass dissolved } / \text { molar mass }}{\text { volume of solvent }}
$$

where the units of molarity are moles per litre or Molar (M). The sequence of solutions was $2 \mathrm{M}, 1.34 \mathrm{M}, 0.134$ $\mathrm{M}$ and $0.0134 \mathrm{M}$ respectively, and in some cases the sequence was followed twice in succession.

For the last set of experiments the same concentrations were used apart from the strongest concentration of $2 \mathrm{M}$, when saturated $\mathrm{KCl}$ solution $(\sim 4 \mathrm{M})$ was introduced, where saturation was determined by the inability of the solution to dissolve any more salt. This saturated solution was then successively diluted with distilled water in ratio steps of $1: 10$ to yield lower concentration ratios to the saturated $\mathrm{KCl}$ solution of 1:10 $(\sim 0.4 \mathrm{M}), 1: 100$ $(\sim 0.04 \mathrm{M})$ and 1:1000 $(\sim 0.004 \mathrm{M})$ respectively. Each time the test solution was changed, the electrodes were rinsed in a beaker of distilled water to ensure any salt deposits would dissolve thereby eliminating past solution memory from the electrode surfaces. The electrodes were immersed in each solution for about 40 minutes for step response testing but in cases where the drift of the electrodes was examined the immersion time was in the range of several days.

\section{Results \& Discussion}

Raw data were recorded for each electrode and an average graph of voltage versus time was plotted as shown in Figure 6. Data for each solution were recorded in standard intervals of 5 seconds for a total of an hour and a half. For the hydration period the intervals were 5 minutes for a total of about 13-14 hours. Three electrodes of each type where tested and their ensemble average for every simultaneous reading was calculated. For every solution, an average value for the electrode voltage in that solution was calculated from the ensemble average values of the three electrodes. Using these results, a graph of average electrode voltage versus chloride ion concentration was plotted for each type of electrode to enable better comparison with the theoretical responses as shown in Figure 7. From the graphs of voltage versus chloride ion concentration the gradient of the line was obtained, hence defining the susceptibility of the electrode to chloride ions, as subsequently tabulated below. 


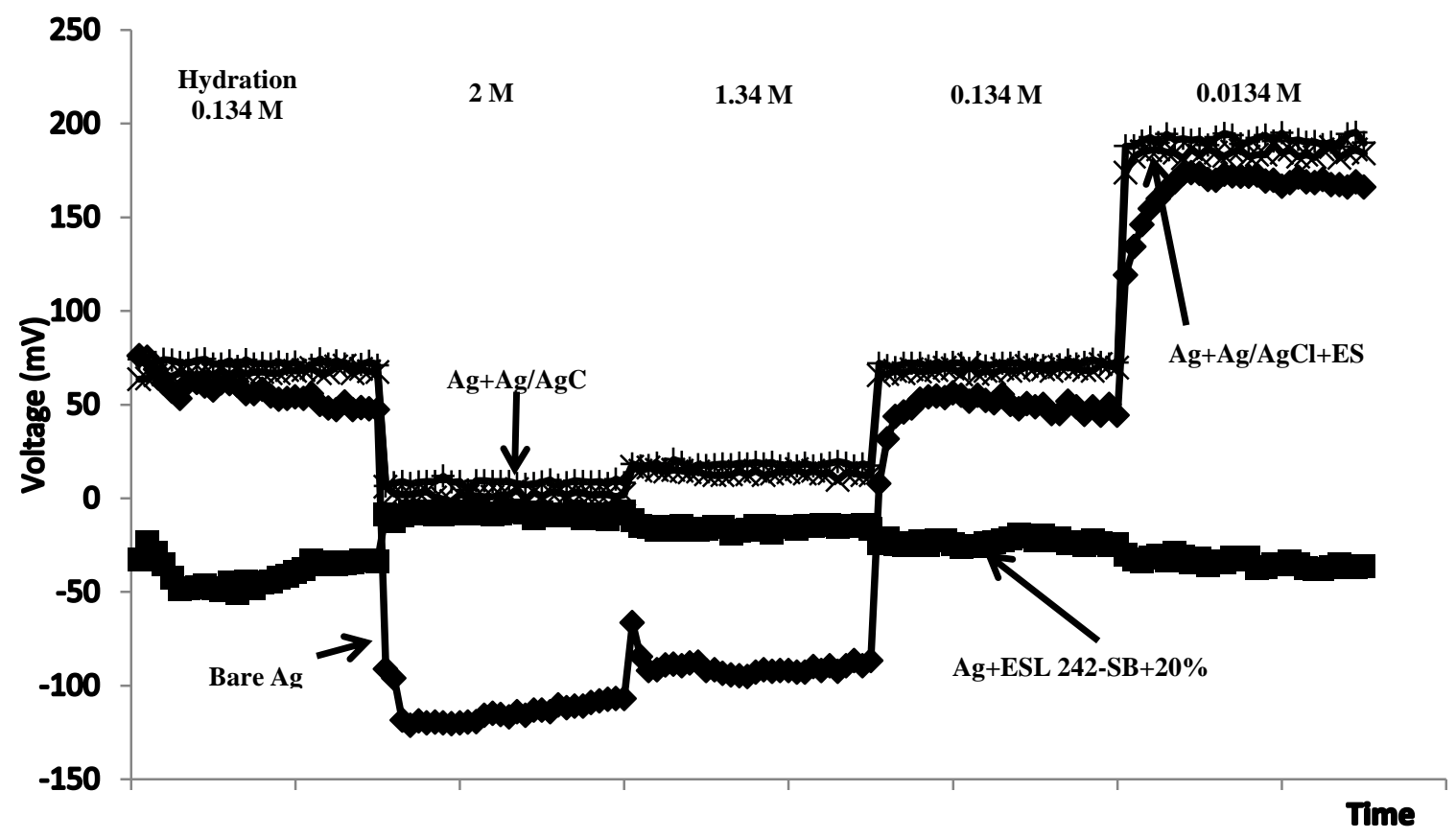

Figure 6: Voltage vs Time in different $\mathrm{KCl}$ concentrations

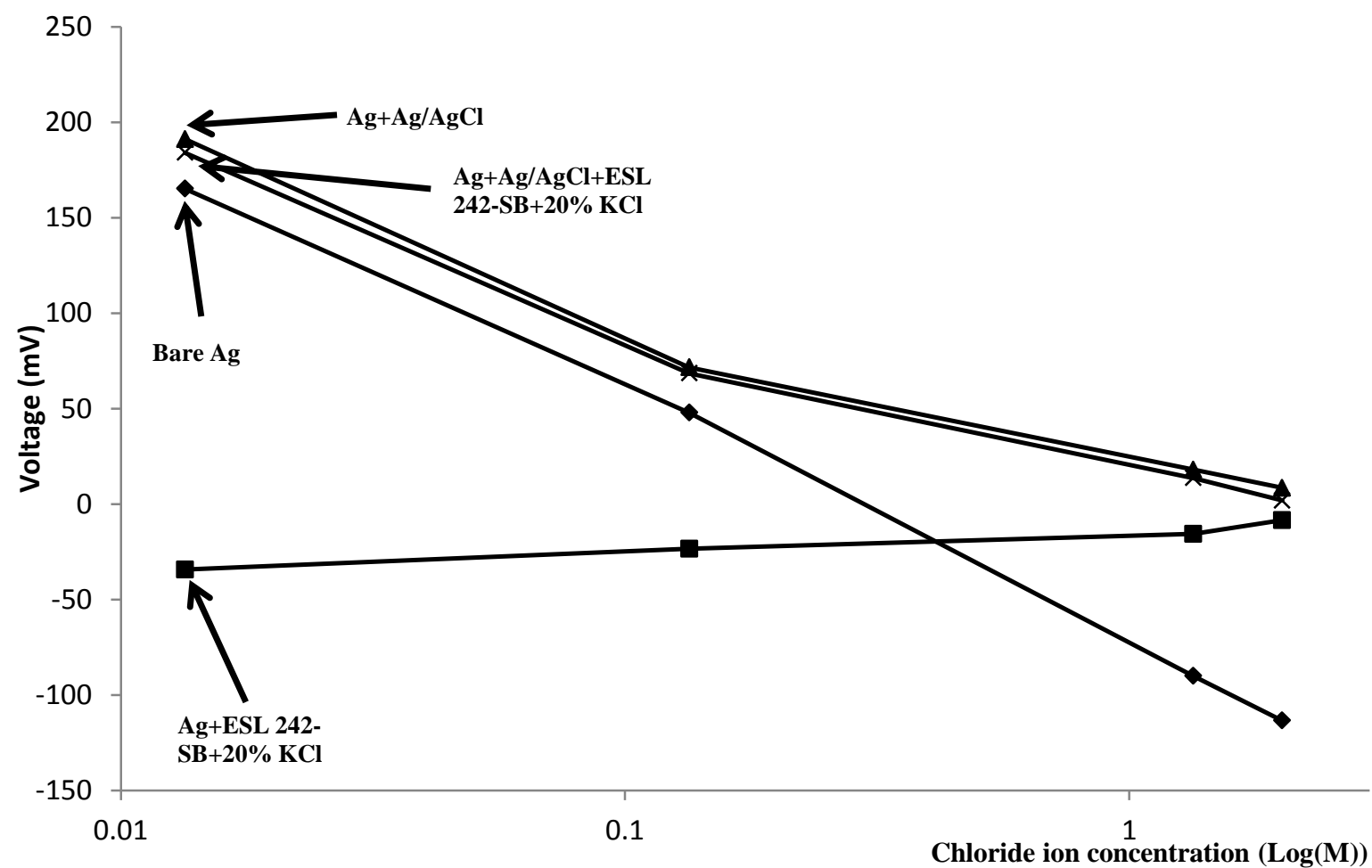

Figure 7: Voltage versus chloride ion concentration on logarithmic scale

Several experiments with different structural types of electrodes were tested by following the same procedure. The results are tabulated and shown in terms of the electrode sensitivity to chloride ions ( $\mathrm{mV} /$ decade change in chloride concentration), the difference in sensitivity between the three electrodes of each type tested, the correlation $\left(\mathrm{R}^{2}\right)$ [9] of their sensitivity with a best fit linear function, and the range of solution concentrations over which the tabulated sensitivity is calculated.

Electrode types were tabulated in separate tables depending on their $\mathrm{Ag} / \mathrm{AgCl}$ layer type. Table 2 shows the results for the electrodes employing only a bare silver layer. The materials used, as listed in the table, are for the layer deposited on top of the bare Ag layer. 
Table 2: Bare Ag electrodes

\begin{tabular}{|c|c|c|c|c|c|}
\hline No & Materials Used & $\begin{array}{l}\text { Sensitivity } \\
\text { (mV/decade) }\end{array}$ & $\begin{array}{c}\text { Sensitivity } \\
\text { difference } \\
\text { between } \\
\text { electrodes }(\mathrm{mV})\end{array}$ & $\mathbf{R}^{2}$ & $\begin{array}{l}\text { Workable } \\
\text { range }(M)\end{array}$ \\
\hline 1 & Bare & -129 & $\begin{array}{l}+2 \\
-2\end{array}$ & 0.998 & all \\
\hline 2 & ESL 242-SB & - & $\begin{array}{l}- \\
-\end{array}$ & - & - \\
\hline 3 & ESL $242-\mathrm{SB}+20 \% \mathrm{KCl}$ & +11 & $\begin{array}{l}+7 \\
-7\end{array}$ & 0.9652 & all \\
\hline 4 & ESL $242-\mathrm{SB}+20 \% \mathrm{KNO}_{3}$ & - & $\begin{array}{l}- \\
-\end{array}$ & - & - \\
\hline 5 & ESL $242-\mathrm{SB}+66 \% \mathrm{KCl}$ & -84 & $\begin{array}{l}+8 \\
-4\end{array}$ & 0.9454 & all \\
\hline 6 & ESL $242-\mathrm{SB}+71 \% \mathrm{KCl}$ & -90 & $\begin{array}{l}+6 \\
-6\end{array}$ & 0.9611 & all \\
\hline 7 & ESL $242-S B+20 \% \mathrm{KCl}+\mathrm{ESL} 242-\mathrm{SB}$ & +2 & $\begin{array}{l}+1 \\
-1\end{array}$ & 0.8762 & all \\
\hline 8 & $\begin{array}{c}\mathrm{ESL} 242-\mathrm{SB}+20 \% \mathrm{KCl}+\mathrm{ESL} 242-\mathrm{SB} \\
+20 \% \mathrm{KCl}\end{array}$ & +2 & $\begin{array}{l}+4 \\
-5\end{array}$ & 0.6214 & all \\
\hline 9 & ESL $242-\mathrm{SB}+50 \% \mathrm{KCl}+\mathrm{ESL} 242-\mathrm{SB}$ & +2 & $\begin{array}{l}+2 \\
-1\end{array}$ & 0.9276 & all \\
\hline 10 & $\begin{array}{c}\text { ESL 242-SB }+50 \% \mathrm{KCl}+\mathrm{ESL} 242-\mathrm{SB} \\
+20 \% \mathrm{KCl}\end{array}$ & +4 & $\begin{array}{l}- \\
-\end{array}$ & 0.8701 & all \\
\hline 11 & ESL $242-S B+66 \% \mathrm{KCl}+\mathrm{ESL} 242-\mathrm{SB}$ & -0.3 & $\begin{array}{l}+1 \\
-1\end{array}$ & 0.32 & $0.0044-0.436$ \\
\hline 12 & $\begin{array}{c}\text { ESL 242-SB }+66 \% \mathrm{KCl}+\mathrm{ESL} 242-\mathrm{SB} \\
+20 \% \mathrm{KCl}\end{array}$ & -3 & $\begin{array}{l}+3 \\
-3 \\
\end{array}$ & 0.0876 & $0.0044-0.436$ \\
\hline
\end{tabular}

All electrodes were hydrated in $0.134 \mathrm{M} \mathrm{KCl}$ solution

Tested range of electrodes 1- 4 was $2 \mathrm{M}-0.0134 \mathrm{M} \mathrm{KCl}$, electrodes $4-12$ in the range $4.35 \mathrm{M}-0.004 \mathrm{M} \mathrm{KCl}$

Workable range: all $=$ whole range tested

Bare Ag electrodes showed a sensitivity of $\sim 130 \mathrm{mV} /$ decade which is approximately double the theoretical Nernstian response. When a layer of pure ESL 242-SB was printed on top of the Ag the response was random and very noisy, which is believed to be because the solution could not easily penetrate the ESL 242-SB layer and therefore the voltage recorded was mainly due to noise from the surroundings. When $\mathrm{KCl}$ was introduced into the polymeric layer of ESL 242-SB the response was completely different. Three different percentages by weight of $\mathrm{KCl}$ were tested with $20 \%, 66 \%$ and $71 \%$ respectively. The sensitivity of this type of electrode decreases with the percentage addition of $\mathrm{KCl}$ in the top layer although it appears that there is an optimum weight percentage. If the $\mathrm{KCl}$ percentage is too low the electrode has a very low conductivity giving noisy responses, while as the percentage increases the conductivity increases. However, above a certain percentage $\mathrm{KCl}$ the ability of the binder to hold the salt on the substrate decreases, which then leads to an increase in the chloride sensitivity of the electrodes.

Adding another layer on top of the $\mathrm{KCl}$ layer significantly decreases the susceptibility of the electrodes. All the electrodes with the added layer have a susceptibility of approximately +2 to $+4 \mathrm{mV} /$ decade in all chloride concentrations, except the types with $66 \% \mathrm{KCl}$, which behave in a stable manner in lower chloride concentrations until the voltage decreases dramatically in saturated chloride solution. As postulated previously, above a certain percentage of added $\mathrm{KCl}$ the paste is unable to hold the $\mathrm{KCl}$ on the electrode sufficiently and this is most probably the reason the voltage decreases so dramatically in saturated solution, as the saturated solution then directly modifies the surface of the electrode. Although it could be said that these electrodes are not $\mathrm{Ag} / \mathrm{AgCl}$ reference electrodes because the $\mathrm{Ag} / \mathrm{AgCl}$ layer is missing, however a SEM scan showed that a $\mathrm{AgCl}$ layer is still present. Figure 8 shows a SEM scan of the cross section of the lower silver layer with the ESL 242-SB $+50 \% \mathrm{KCl}$ layer on top, where the two layers can clearly be seen. As shown in the figure, chlorine atoms were found at the point on the silver layer where the readings were taken (Spectrum 1), where the percentages of each species are as shown in Table 1, which tends to suggest that a thin layer of $\mathrm{AgCl}$ has formed. The scanned sample shown in Figure 8 is a new non-tested sample which means that the $\mathrm{AgCl}$ is not formed during testing. This was further confirmed when an identical electrode was scanned and the species percentages were found to be approximately the same. Based on this evidence, the $\mathrm{AgCl}$ layer is formed during fabrication of the electrode and it is likely that the amount of $\mathrm{AgCl}$ formed is determined by the $\mathrm{KCl}$ concentration that is used in the layer printed on top of the Ag. 
Table 3:SEM scan results

\begin{tabular}{l|cc}
\hline Element & Weight \% & Atomic \% \\
& & \\
$\mathrm{Al} \mathrm{K}$ & 1.18 & 4.45 \\
$\mathrm{Si} \mathrm{K}$ & 0.24 & 0.87 \\
$\mathrm{Cl} \mathrm{K}$ & 0.88 & 2.54 \\
$\mathrm{Ag} \mathrm{L}$ & 97.69 & 92.14 \\
& & \\
Totals & 100.00 & \\
\hline
\end{tabular}

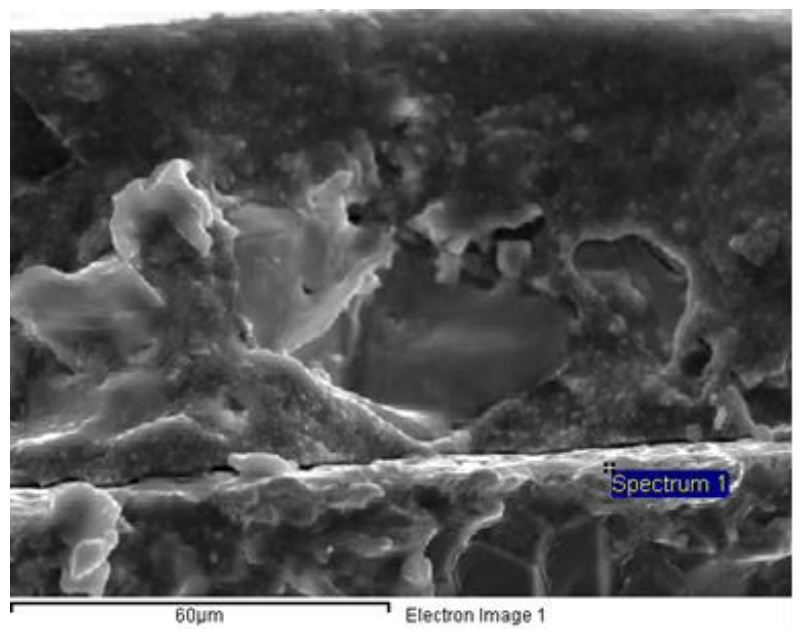

Figure 8: SEM scan of the cross section of a Bare Ag electrode with ESL 242-SB + 50\% KCl layer deposited on top

Other types of $\mathrm{Ag} / \mathrm{AgCl}$ pastes were used to investigate the parameters affecting the performance of the electrodes. One of the pastes was the polymeric C61003P7 from Gwent Electronic Materials containing a ratio of $\mathrm{Ag}$ to $\mathrm{AgCl}$ of 3:2. The only difference in this type of electrode is the additional $\mathrm{Ag} / \mathrm{AgCl}$ layer deposited above the Ag layer.

Table 4: Polymer Ag/AgCl GEM C61003P7

\begin{tabular}{|c|c|c|c|c|c|}
\hline No & Materials Used & $\begin{array}{c}\text { Sensitivity } \\
\text { (mV/decade) }\end{array}$ & $\begin{array}{c}\text { Sensitivity } \\
\text { difference } \\
\text { between } \\
\text { electrodes }(m \mathbf{m})\end{array}$ & $\mathbf{R}^{2}$ & $\begin{array}{l}\text { Workable } \\
\text { range (M) }\end{array}$ \\
\hline 1 & Bare & -82 & $\begin{array}{l}- \\
-\end{array}$ & 0.9586 & all \\
\hline 2 & Bare Fired & -122 & $\begin{array}{l}+20 \\
-13\end{array}$ & 0.9985 & all \\
\hline 3 & ESL 242-SB & -82 & $\begin{array}{l}+1 \\
-1\end{array}$ & 0.9625 & all \\
\hline 4 & ESL 242-SB Fired & -26 & $\begin{array}{l}+1 \\
-1\end{array}$ & 0.9405 & $0.134-2$ \\
\hline 5 & ESL 242-SB $6 \% \mathrm{KCl}$ & -54 & - & 1 & all \\
\hline 6 & ESL 242-SB $20 \% \mathrm{KCl}$ & -81 & $\begin{array}{l}- \\
-1\end{array}$ & 0.966 & all \\
\hline 7 & ESL $242-S B+20 \% \mathrm{KCl}$ Fired & -1 & $\begin{array}{l}+3 \\
-2\end{array}$ & 0.9469 & $0.134-2$ \\
\hline 8 & ESL $242-S B 33 \% \mathrm{KCl}$ & -48 & $\begin{array}{l}+1 \\
-1\end{array}$ & 0.9976 & all \\
\hline 9 & ESL 242-SB $50 \% \mathrm{KCl}$ & -51 & $\begin{array}{l}+1 \\
-1\end{array}$ & 0.9986 & all \\
\hline 10 & ESL $242-S B \quad 66 \% \mathrm{KCl}$ & -58 & - & 0.995 & all \\
\hline 11 & ESL 242-SB 71\% KCl & -58 & - & 0.9951 & all \\
\hline
\end{tabular}

*All electrodes were hydrated in $0.134 \mathrm{M}$ of $\mathrm{KCl}$ solution

**1-9 Tested in range $2 \mathrm{M}-0.0134 \mathrm{M} \mathrm{KCl}, 10-11$ in the range $4.35 \mathrm{M}-0.004 \mathrm{M}$

**** Workable range: all $=$ whole range tested

The bare polymer $\mathrm{Ag} / \mathrm{AgCl}$ electrodes exhibited a super-Nernstian sensitivity of approx. $-82 \mathrm{mV} / \mathrm{dec}$ ade. When the ESL 242-SB layer with no KCl salt was printed on top the response became very noisy but showed a similar sensitivity. As shown in Table 4, the variation of the sensitivity is relatively small between the different levels of $\mathrm{KCl}$ contained in the top layer and close to the Nernstian value, except in the case of $20 \%, \mathrm{KCl}$, which shows an apparently anomalous susceptibility of $-81 \mathrm{mV} /$ decade. This may have been the result of a fabrication error when this particular batch of electrodes was fabricated.

In Table 4 there are two types of electrodes designated as 'fired', which indicates that the paste was fired at $850^{\circ} \mathrm{C}$ instead of the recommended curing temperature of $80^{\circ} \mathrm{C}$ (accidentally at first but then later on purpose). In that situation, due to the high temperature involved, the $\mathrm{AgCl}$ very likely decomposes or reacts with some 
other species (e.g. oxygen), with the result that chlorine is evolved. To investigate this, SEM scans were performed of a properly cured polymer $\mathrm{Ag} / \mathrm{AgCl}$ paste and the 'fired' one. In the case of the 'fired' $\mathrm{Ag} / \mathrm{AgCl}$ electrode the amount of chloride present was so low that it was approximately the same as the percentage found on the bare $\mathrm{Ag}$ electrode. In fact, the performances of the bare $\mathrm{Ag}$ and fired polymer $\mathrm{Ag} / \mathrm{AgCl}$ electrodes were very similar, which reinforces the concept that the performance is critically influenced by the $\mathrm{Ag}$ to $\mathrm{AgCl}$ ratio.

Table 5 and 
Table 6 show another two types of $\mathrm{Ag} / \mathrm{AgCl}$ pastes that were tested, in which a low temperature glass binder was used with $\mathrm{Ag} / \mathrm{AgCl}$ ratio of 1:1. These two types of $\mathrm{Ag} / \mathrm{AgCl}$ pastes perform similarly and are affected by the same amount for each varying parameter with the same trend being observed for the percentage of $\mathrm{KCl}$ in the ESL 242-SB layer. At low levels of contained $\mathrm{KCl}$ the sensitivity is high compared to the bare $\mathrm{Ag} / \mathrm{AgCl}$ electrode while as the $\mathrm{KCl}$ level increases the electrode chloride sensitivity decreases up to a point (approx. 20\%) where it starts increasing again. Above a certain percentage the polymer paste is less able to hold the $\mathrm{KCl}$ on the electrode and therefore the sensitivity increases reaching a value close to the Nernstian response. These two glass bound electrode types were also fired at higher temperatures to check if the same response is observed and another SEM scan showed approximately the same results as for the GEM C61003P7 paste, while the performance was found to be similar to that of the 'fired' polymer (row 5, Tables 5 and 6).

The two glass bound electrode types were also tested with an extra layer of ESL 242-SB with $20 \% \mathrm{KNO}_{3}$ deposited as a top layer. This extra layer results in a better stability in different concentrations of $\mathrm{KCl}$ but that is believed to be most probably because of the extra ESL 242-SB layer acting as a membrane holding the $\mathrm{KCl}$ on the electrode at the same time as allowing water soluble ions to pass through and close the circuit. This theory appears to be substantiated by the similar performance of the bare Ag electrodes with the extra $\mathrm{KCl}$ containing ESL 242-SB layer on top (Table 3).

Table 5: Glassy Ag/AgCl PPCFB2

\begin{tabular}{|c|c|c|c|c|c|}
\hline No & Materials Used & $\begin{array}{c}\text { Sensitivity } \\
(\mathrm{mV} / \text { decade })\end{array}$ & $\begin{array}{c}\text { Sensitivity } \\
\text { difference } \\
\text { between } \\
\text { electrodes }(\mathbf{m V})\end{array}$ & $\mathbf{R}^{2}$ & $\begin{array}{l}\text { Workable } \\
\text { range }(M)\end{array}$ \\
\hline 1 & Bare & -50 & $\begin{array}{l}+4 \\
-4\end{array}$ & 0.999 & all \\
\hline 2 & Bare Fired & -35 & $\begin{array}{l}+7 \\
-8\end{array}$ & 0.583 & all \\
\hline 3 & ESL $242-\mathrm{SB} 6 \% \mathrm{KCl}$ & -45 & $\begin{array}{l}+1 \\
-1\end{array}$ & 0.998 & all \\
\hline 4 & ESL $242-S B 20 \% \mathrm{KCl}$ & -43 & $\begin{array}{l}+1 \\
-1\end{array}$ & 0.994 & all \\
\hline 5 & ESL $242-\mathrm{SB}+20 \% \mathrm{KCl}$ Fired & -8 & $\begin{array}{l}+4 \\
-4\end{array}$ & 0.174 & all \\
\hline 6 & ESL $242-S B \quad 66 \% \mathrm{KCl}$ & -62 & $\begin{array}{l}- \\
-1\end{array}$ & 0.98 & all \\
\hline 7 & ESL $242-S B ~ 71 \% \mathrm{KCl}$ & -66 & $\begin{array}{l}+1 \\
-1\end{array}$ & 0.99 & all \\
\hline 8 & $\begin{array}{c}\text { ESL } 242-\mathrm{SB} 20 \% \mathrm{KCl}+\mathrm{ESL} \\
242-\mathrm{SB} 20 \% \mathrm{KNO}_{3}\end{array}$ & -15 & - & 0.907 & all \\
\hline
\end{tabular}

*All electrodes were hydrated in $0.134 \mathrm{M} \mathrm{KCl}$ solution

$* * 1,3,4$ Tested in the range $2 \mathrm{M}-0.0134 \mathrm{M} \mathrm{KCl} ; 2,5-8$ in the range $4.35 \mathrm{M}-0.004 \mathrm{M} \mathrm{KCl}$

*** Workable range: all $=$ whole range tested in 
Table 6: Glassy Ag/AgCl PPCFC3

\begin{tabular}{|c|c|c|c|c|c|}
\hline No & Materials Used & $\begin{array}{c}\text { Sensitivity } \\
\text { (mV/decade) }\end{array}$ & $\begin{array}{c}\text { Sensitivity } \\
\text { difference between } \\
\text { electrodes }(\mathbf{m V})\end{array}$ & $\mathbf{R}^{2}$ & $\begin{array}{l}\text { Workable } \\
\text { range }(\mathrm{M})\end{array}$ \\
\hline 1 & Bare & -44 & $\begin{array}{r}+17 \\
-17\end{array}$ & 0.9996 & all \\
\hline 2 & Bare Fired & -80 & $\begin{array}{l}+21 \\
-35\end{array}$ & 0.9331 & all \\
\hline 3 & ESL $242-\mathrm{SB} 6 \% \mathrm{KCl}$ & -33 & $\begin{array}{l}+5 \\
-5\end{array}$ & 0.9984 & all \\
\hline 4 & ESL $242-S B 20 \% \mathrm{KCl}$ & -29 & $\begin{array}{c}+10 \\
-4\end{array}$ & 0.9927 & all \\
\hline 5 & ESL 242-SB $20 \% \mathrm{KCl}$ Fired & -5 & $\begin{array}{l}+1 \\
-1\end{array}$ & 0.4754 & $0.0044-2$ \\
\hline 6 & ESL 242-SB $66 \% \mathrm{KCl}$ & -59 & $\begin{array}{l}+1 \\
-1\end{array}$ & 0.9837 & all \\
\hline 7 & ESL 242-SB $71 \% \mathrm{KCl}$ & -61 & $\begin{array}{l}- \\
-\end{array}$ & 0.9903 & all \\
\hline 8 & $\begin{array}{c}\text { ESL } 242-\mathrm{SB} 20 \% \mathrm{KCl}+\mathrm{ESL} \\
242-\mathrm{SB} 20 \% \mathrm{KNO}_{3}\end{array}$ & +4 & $\begin{array}{l}+1 \\
-1\end{array}$ & 0.8819 & $0.0044-2$ \\
\hline
\end{tabular}

*All electrodes were hydrated in $0.134 \mathrm{M} \mathrm{KCl}$ solution

$* * 1,3,4$ Tested in the range $2 \mathrm{M}-0.0134 \mathrm{M} \mathrm{KCl} ; 2,5-8$ in the range $4.35 \mathrm{M}-0.004 \mathrm{M} \mathrm{KCl}$

*** Workable range: all $=$ whole range tested in

Selected electrode types were sequentially immersed into three different $\mathrm{pH}$ buffers, chosen as $\mathrm{pH} 4, \mathrm{pH} 7$ and $\mathrm{pH} 10$, in a test solution sequence of $\mathrm{pH}$ 7-4-7-10-7-4-7-10. The averaged results from 3 electrodes of each type are presented in Figure 9. The graph of voltage against $\mathrm{pH}$ (Figure 10) shows that the reference electrode potentials are affected by the $\mathrm{pH}$, but only up to a point that is relatively insignificant for most electrochemical applications. The variation of the potential for some of the electrodes was in the range of $\pm 5 \mathrm{mV}$, which is equivalent to \pm 0.1 of a $\mathrm{pH}$ unit for a near Nernstian thick film $\mathrm{pH}$ sensor, such as those reported previously by this research group [10].

From Figure 9 it can be seen that electrodes containing a higher percentage of $\mathrm{KCl}$ in their upper layers drift more than those with lower $\mathrm{KCl}$ concentrations. The electrodes were tested in a cyclic manner in the different $\mathrm{pH}$ solutions and it can be observed that the potential of the higher $\mathrm{KCl}$ containing electrodes in the same $\mathrm{pH}$ buffer increases slightly each time.

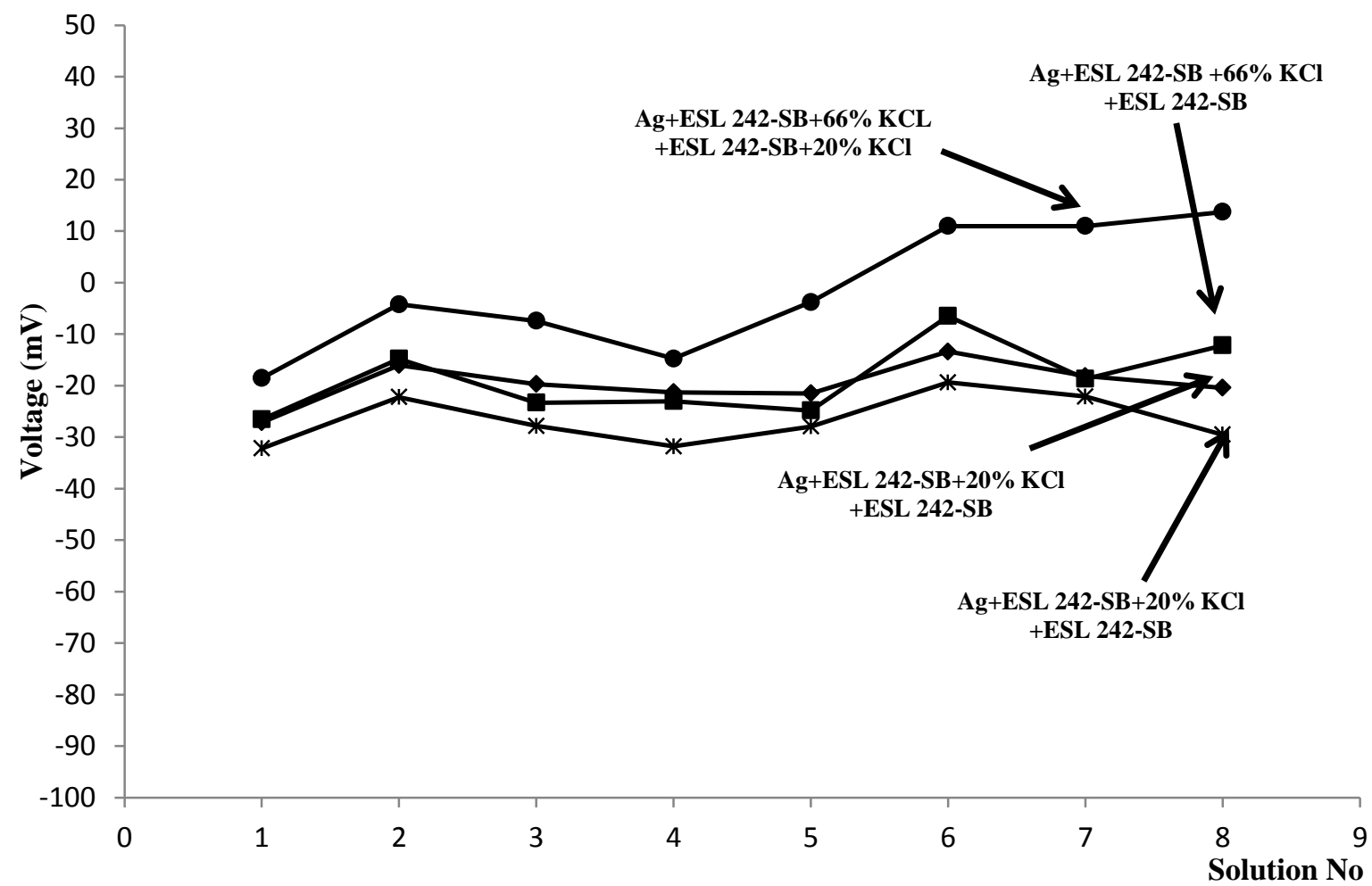

Figure 9: reference electrode potential versus commercial liquid filled $\mathrm{Ag} / \mathrm{AgCl}$ reference electrode 


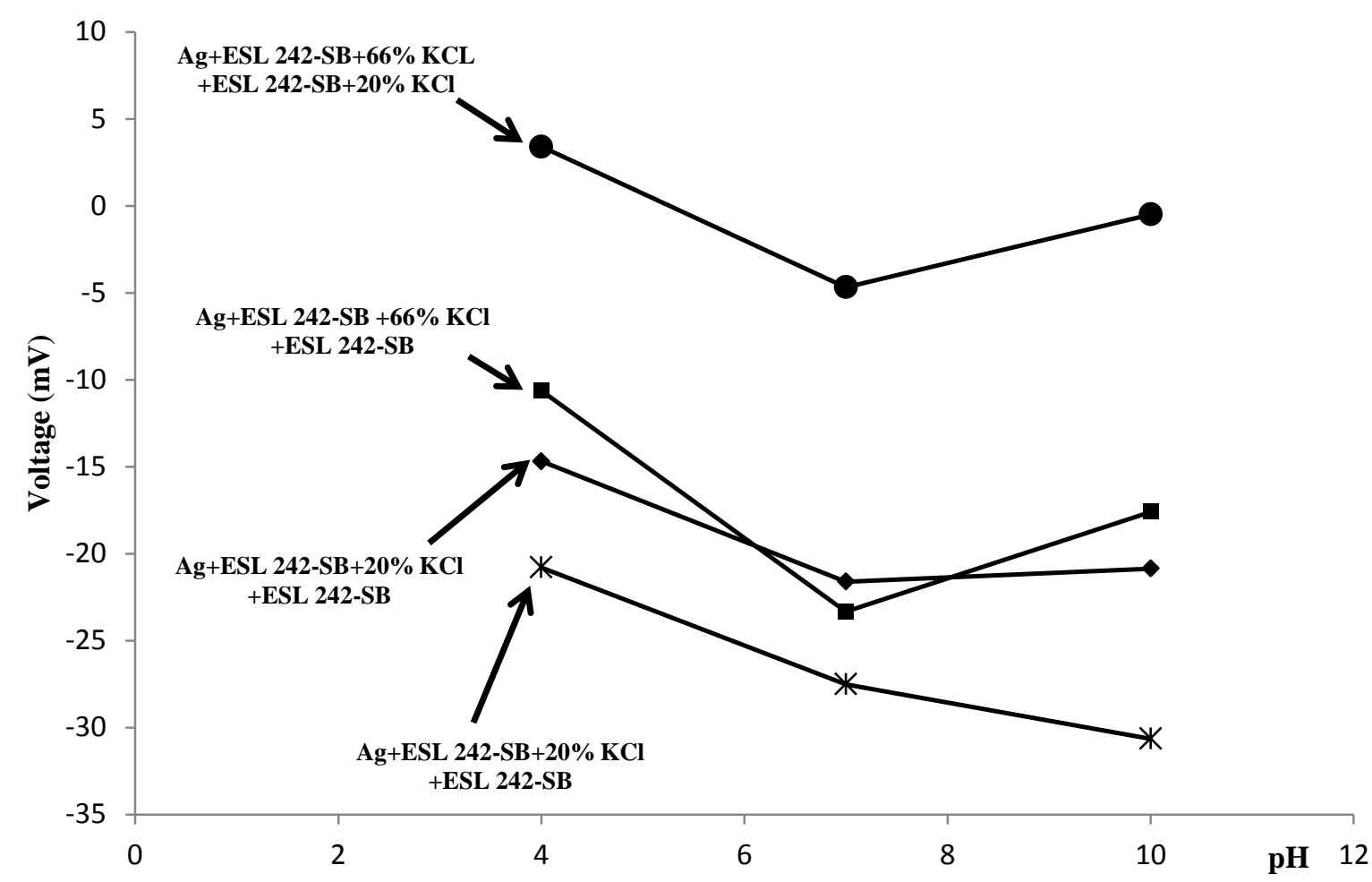

Figure 10: reference electrode potential measured versus commercial liquid-filled $\mathrm{Ag} / \mathrm{AgCl}$ reference electrode as a function of $\mathrm{pH}$

\section{Conclusions}

Adding another layer of ESL 242-SB with $\mathrm{KCl}$ on top can also affect the performance of the electrodes. At low percentages of $\mathrm{KCl}$ in the paste the electrodes have low conductivity, making them more susceptible to noise, as the percentage $\mathrm{KCl}$ increases so the noise decreases. Above a certain percentage point the paste has insufficient mechanical stability to hold the $\mathrm{KCl}$ on the electrode and the $\mathrm{KCl}$ dissolves more easily into the solution increasing the chloride sensitivity of the electrodes.

Firing the $\mathrm{Ag} / \mathrm{AgCl}$ layer at $850^{\circ} \mathrm{C}$ has proven to leave the electrode without any $\mathrm{AgCl}$, making it into effectively a bare Ag electrode. From the SEM scans, the chlorine levels in these electrodes were similar to those of the bare $\mathrm{Ag}$ electrodes, where some $\mathrm{AgCl}$ is formed during fabrication of the electrodes. Most probably some of the surface of the underlying $\mathrm{Ag}$ reacts with the $\mathrm{KCl}$ forming a small amount of $\mathrm{AgCl}$ when the $\mathrm{ESL}$ 242-SB layer containing $\mathrm{KCl}$ is cured at $150^{\circ} \mathrm{C}$.

When another layer of ESL 242-SB is printed on top of the already printed ESL 242-SB with $\mathrm{KCl}$, the performance of the electrodes improves dramatically. The chloride sensitivity of the electrodes decreases to $\sim+2 \mathrm{mV} /$ decade (equivalent to $0.04 \mathrm{pH}$ units/decade) which makes the electrodes stable enough to be used at any chloride ion concentration. In this case it is believed that the top layer acts as a membrane holding the $\mathrm{KCl}$ on the electrode but at the same time allowing a sufficient level of water soluble ions to pass through and complete the circuit. If higher levels of $\mathrm{KCl}$ are added to the top layer the electrode sensitivity increases because more pathways are now present for the water to pass through and "wash out" the $\mathrm{KCl}$ of the underlying layer.

The electrodes with best stabilities were also tested in different $\mathrm{pH}$ buffers giving satisfactory results with variations in electrode potentials of less than $\pm 5 \mathrm{mV}$ in the range from $\mathrm{pH} 4$ to $\mathrm{pH} 10$. These variations can be considered relatively acceptable, since for most conventional types of $\mathrm{pH}$ sensor every unit change in $\mathrm{pH}$ produces a change of $59 \mathrm{mV}$, hence resulting in an equivalent error due to the reference electrode of less than $\pm 0.1 \mathrm{pH}$. The electrodes were immersed in the $\mathrm{pH}$ buffers in various sequences to check for any modifications the $\mathrm{pH}$ buffers might have on the electrodes (e.g. hysteresis) and the results were also found to be satisfactory 
since the difference in voltage between each response curve was found to be in the range of one or two millivolts which can also be considered well within the instrumental uncertainty.

\section{Acknowledgements}

The authors wish to thank the UK Environment Agency and the National Environmental Research Council for partially supporting this work.

\section{References}

[1] A.Gac, J.K. Atkinson, Z. Zhang, R.P. Sion, A comparison of thick-film chemical sensor characteristics in laboratory and on-line industrial process applications, Measurement Science and Technology, 13 (2002) 2062-2073.

[2] D. Desmond, B. Lane, J. Alderman, J.D. Glennon, D. Diamond, D.W.M. Arrigan, Evaluation of miniaturised solid state reference electrodes on a silicon based component, Sensors and Actuators B: Chemical, 44 (1997) 389-396.

[3] J.K. Atkinson, M. Glanc, M. Prakorbjanya, R.P. Sion, E. Garcia-Breijo, Screen Printed Thick Film Subterranean and Subaqueous Environmental Chemical Sensor Arrays, in: 13th Electronics Packaging Technology Conference, Singapore (2011).

[4] Ł. Tymeckia, E. Zwierkowskab, R. Konckia, Screen-printed reference electrodes for potentiometric measurements, Analytica Chimica Acta, 526 (2004) 3-11.

[5] D.J.G. Ives, G.J. Janz, Reference Electrodes: Theory and practise, Academic Press, Berkeley Square House, London W1, (1961).

[6] A.W.J. Cranny and J.K. Atkinson, Thick film silver-silver chloride reference electrodes, Measurement Science and Technology, 9 (1998) 1557-1565.

[7] J.K. Atkinson, M. Glanc, P. Boltryk, M. Sophocleous, E. Garcia-Breijo, An investigation into the effect of fabrication parameter variation on the characteristics of screen-printed thick-film silver/silver chloride reference electrodes, Microelectronics International, 28 (2011) 49-52.

[8] U. Guth, F. Gerlach, M. Decker, W. Oelßner, W. Vonau, Solid-state reference electrodes for potentiometric sensors, Journal of Solid State Electrochemistry, 13 (2009) 27-39.

[9] R.G.D. Steel and J.H. Torrie, Principles and Procedures of Statistics, New York, (1960).

[10] J.A. Mihell, and J.K. Atkinson, Planar thick-film $\mathrm{pH}$ electrodes based on ruthenium dioxide hydrate, Sensors and Actuators B: Chemical, 48, (1-3), (1998) 505-511. 